\title{
BMJ
}

\section{Dynamic spread of happiness in a large social network: longitudinal analysis over 20 years in the Framingham Heart Study}

\author{
James H Fowler, associate professor, ${ }^{1}$ Nicholas A Christakis, professor ${ }^{2}$
}

'Department of Political Science, University of California, San Diego, CA, USA

${ }^{2}$ Department of Health Care Policy, Harvard Medical School, and Department of Sociology, Harvard University, Cambridge, MA, USA

Correspondence to: $\mathrm{N}$ A Christakis christak@hcp.med.harvard.edu

Cite this as: $B M J$ 2008;337:a2338 doi:10.1136/bmj.a2338

\section{ABSTRACT}

Objectives To evaluate whether happiness can spread from person to person and whether niches of happiness form within social networks.

Design Longitudinal social network analysis.

Setting Framingham Heart Study social network.

Participants 4739 individuals followed from 1983 to 2003.

Main outcome measures Happiness measured with validated four item scale; broad array of attributes of social networks and diverse social ties.

Results Clusters of happy and unhappy people are visible in the network, and the relationship between people's happiness extends up to three degrees of separation (for example, to the friends of one's friends' friends). People who are surrounded by many happy people and those who are central in the network are more likely to become happy in the future. Longitudinal statistical models suggest that clusters of happiness result from the spread of happiness and not just a tendency for people to associate with similar individuals. A friend who lives within a mile (about $1.6 \mathrm{~km}$ ) and who becomes happy increases the probability that a person is happy by $25 \%$ (95\% confidence interval $1 \%$ to $57 \%$ ). Similar effects are seen in coresident spouses ( $8 \%, 0.2 \%$ to $16 \%)$, siblings who live within a mile $(14 \%, 1 \%$ to $28 \%$ ), and next door neighbours (34\%, $7 \%$ to $70 \%$ ). Effects are not seen between coworkers. The effect decays with time and with geographical separation. Conclusions People's happiness depends on the happiness of others with whom they are connected. This provides further justification for seeing happiness, like health, as a collective phenomenon.

\section{INTRODUCTION}

Happiness is a fundamental object of human existence, ${ }^{1}$ so much so that the World Health Organization is increasingly emphasising happiness as a component of health. ${ }^{2}$ Happiness is determined by a complex set of voluntary and involuntary factors. Researchers in medicine, ${ }^{3}$ economics, ${ }^{145}$ psychology, ${ }^{67}$ neuroscience, ${ }^{8}$ and evolutionary biology ${ }^{9}$ have identified a broad range of stimuli to happiness (or unhappiness), ${ }^{1}$ including lottery wins, ${ }^{10}$ elections,${ }^{7}$ income,${ }^{1}$ job loss,${ }^{11}$ socioeconomic inequality, ${ }^{12}{ }^{13}$ divorce, ${ }^{1}$ illness, ${ }^{14}$ bereavement,${ }^{15}$ and genes. ${ }^{916}$ These studies, however, have not addressed a possibly key determinant of human happiness: the happiness of others.

Emotional states can be transferred directly from one individual to another by mimicry and "emotional contagion," 17 perhaps by the copying of emotionally relevant bodily actions, particularly facial expressions, seen in others. ${ }^{18-20}$ People can "catch" emotional states they observe in others over time frames ranging from seconds to weeks. ${ }^{1721-23}$ For example, students randomly assigned to a mildly depressed room-mate became increasingly depressed over a three month period, ${ }^{24}$ and the possibility of emotional contagion between strangers, even those in ephemeral contact, has been documented by the effects of "service with a smile" on customer satisfaction and tipping. ${ }^{2526}$

Yet, despite the evidence that certain emotions might spread over short periods from person to person, little is known about the role of social networks in happiness or about whether happiness might spread, by a diverse set of mechanisms, over longer periods or more widely in social networks. As diverse phenomena can spread in social networks, ${ }^{27-35}$ we investigated whether happiness also does so. We were particularly interested in whether the spread of happiness pertains not just to direct relationships (such as friends) but also to indirect relationships (such as friends of friends) and whether there are geographical or temporal constraints on the spread of happiness through a social network.

\section{METHODS}

\section{Participants}

The Framingham Heart Study was initiated in 1948, when 5209 people in Framingham, Massachusetts, were enrolled into the "original cohort." ${ }^{36}$ In 1971, the "offspring cohort," composed of most of the children of the original cohort, and their spouses, was enrolled. ${ }^{37}$ This cohort of 5124 people has had almost no loss to follow-up other than death (only 10 people dropped out). Enrolment of the so called "third generation cohort," consisting of 4095 children of the offspring cohort, began in 2002. The Framingham Heart Study also involves certain other smaller cohorts (such as a 
minority over-sample called the OMNI cohort, enrolled in 1995). At regular intervals participants in all these cohorts come to a central facility for detailed examinations and collection of survey data.

\section{Network ascertainment}

We used the offspring cohort as the source of $5124 \mathrm{key}$ individuals to study - whom we term "egos." Each ego in this cohort is connected to other people via friendship, family, spousal, neighbour, and coworker relationships. Each relationship is a "social tie." Each person who has a relationship with an ego was called an "alter." For example, one ego in the offspring cohort had 18 alters: a mother, a father, a sister, two brothers, three children, two friends, five neighbours, and three coworkers. We wanted to know how each of these alters influences an ego. Many of the alters also happened to be members of a studied cohort in Framingham, which means that we had access to detailed information about them as well. Overall, within the entire Framingham Heart Study social network, composed of both the egos and any detected alters in any Framingham Heart Study cohort, there were 12067 individuals who were connected at some point in 1971-2003.

To create the network dataset, we computerised information about the offspring cohort from archived handwritten administrative tracking sheets that had been used since 1971 to identify people close to participants for the purpose of follow-up. These documents contain valuable social network information because participants were asked to identify their relatives, "close friends," place of residence, and place of work to ensure they could be contacted every two to

\section{Glossary}

- Ego: the focal individual; this is the person whose behaviour is being analysed

- Alter: a person connected to the ego; this is the person who is potentially influencing the behaviour of the ego

- Node: an object that may or may not be connected to other objects in a network; here, these are people in the Framingham Heart Study cohorts

- Tie: a connection between two nodes that can be either one way (directed) or two way (bilateral, or mutual); here, all family and spouse ties are bilateral (sibling, coworker, spouse), but friendship ties are directional as a person might name someone as a friend who does not name them in return

- Homophily: the tendency for people to choose relationships with people who have similar attributes

- Component: a group of nodes that is a subset of a full network and in which each node is connected by at least one path to every other node in the same component

- Cluster: a group of nodes of a certain type that is a subset of a full network and in which each node is connected by at least one path via nodes of the same type to every other node in the same group-for example, a cluster of happy people connected by at least one path via other happy people to all the other people in their cluster

- Degree of separation: the social distance of two individuals as measured by the smallest number of intermediary ties between one individual and the other within the network. For a given ego, alters are degree 1 as they are directly connected to the ego. Nodes that are connected to the alters but not the ego are degree 2 (alters' alters). Nodes that are connected to the alters' alters but not the ego are degree 3 , and so on. This is also known as the "geodesic distance" four years for follow-up. In the field of network science, such procedures for identifying social ties between individuals are known as "name generators." 38

The ascertainment of social ties in the Framingham Heart Study was wide and systematic. The study recorded complete information about all first order relatives (parents, spouses, siblings, children), whether alive or dead, and at least one close friend at up to seven examinations from 1971 to 2003. Detailed information on home address was also captured at each time point, which we geocoded to determine neighbour relationships. Specific information about place of employment at each wave allowed us to identify ties to coworkers within the network.

Our dataset identifies the network links among participants longitudinally, an unusual and advantageous feature. Over the course of follow-up, the participants spread out across the United States but continued to participate in the Framingham Heart Study. As a person's family changed because of birth, death, marriage, or divorce, and as their contacts changed because of residential moves, new places of employment, or new friendships, this information was captured. For any given ego, a particular alter can be in only one mutually exclusive category - that is, spouse, sibling, friend, coworker, or neighbour.

There were 53228 observed social ties between the 5124 egos and any other alters in any of the Framingham Heart Study cohorts, yielding an average of 10.4 ties to family, friends, and coworkers over the course of follow-up. Additional ties to neighbours were also ascertained, based on information about place of residence, but they are not included in the foregoing count as the number of neighbour ties depends on how "neighbour" is defined (for example, whether we restrict the definition to immediate, next door neighbours, or neighbours residing on the same block within 25 or 100 metres, etc).

Given the compact nature of the Framingham social network in the period 1971-2007, many of the nominated contacts were also participants in one or another Framingham Heart Study cohort ${ }^{3234}$ so we have detailed survey and physical examination information about both the ego and the alter. For example, $83 \%$ of egos' spouses were directly and repeatedly observed and $87 \%$ of egos with siblings had at least one sibling who also participated in the Framingham Heart Study. For $39 \%$ of the egos, at least one coworker participated in the study. For $10 \%$ of the egos, an immediate neighbour was also in the Framingham Heart Study.

Importantly, $45 \%$ of the 5124 egos were connected via friendship to another person in the study; there were 3604 unique observed friendships for an average of 0.7 friendship ties per ego. There was substantia variation from person to person, ranging from several people with no friends to one person who was nominated as a friend by eight different Framingham Heart Study participants. Because friendship identifications are directional, we can study three different types. An "ego perceived friend" means the ego 
nominates an alter as a friend, but the nomination is not reciprocated. In this case the ego thinks of the alter as a friend, but the alter might not think of the ego as a friend. An "alter perceived friend" means that an alter nominates the ego as a friend but not vice versa. Here, the ego might not feel any closer to the alter than he or she would to a stranger. Finally, a "mutual friend" is one in which the nomination is reciprocal.

We can be reasonably confident that when someone names someone else as a friend, then the namer feels close to or esteems the namee. We should not, however, read too much into a particular failed nomination. The namer might have several equally good friends and might simply have omitted one or more of them. On the other hand, we would expect on

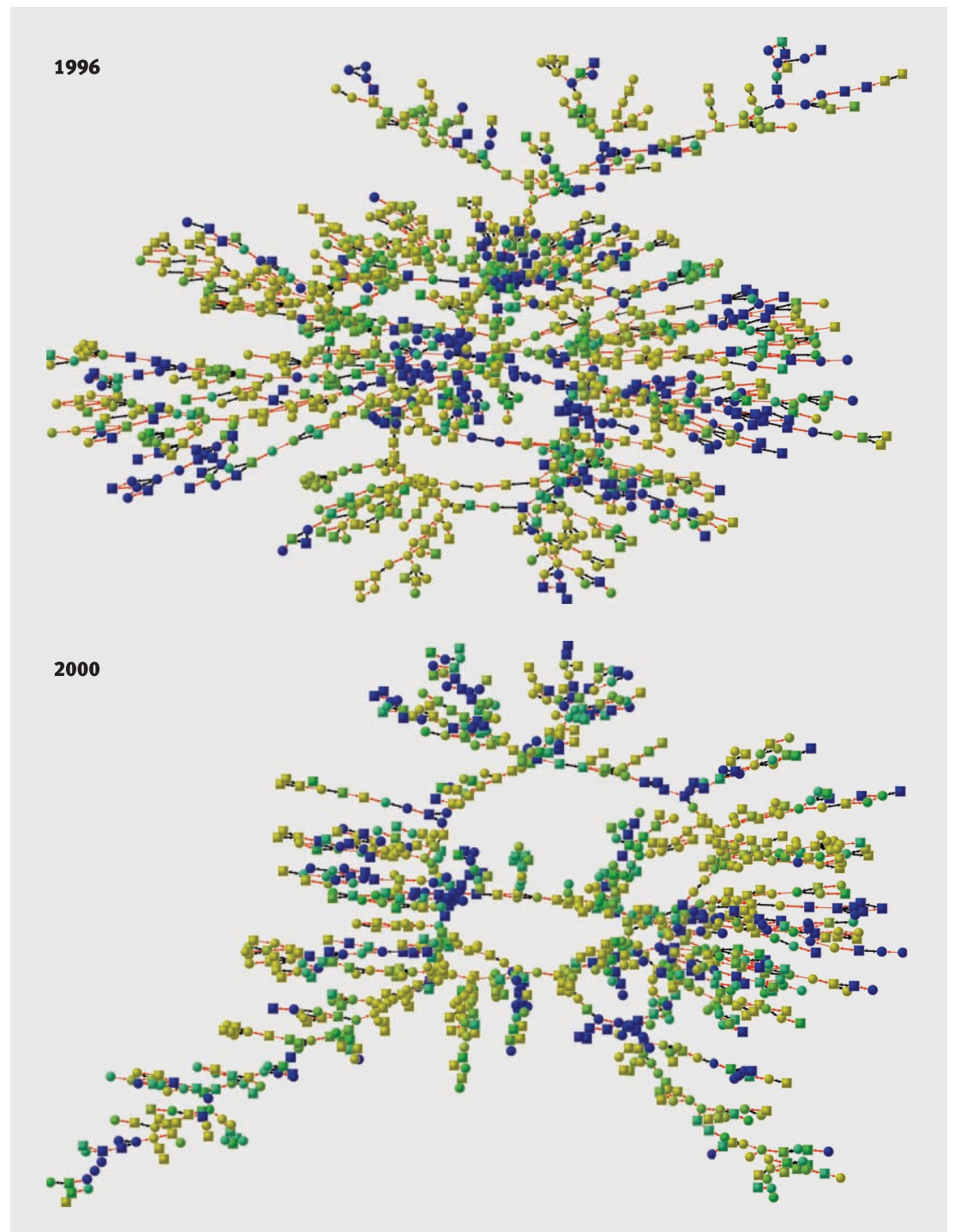

Fig 1 | Happiness clusters in the Framingham social network. Graphs show largest component of friends, spouses, and siblings at exam 6 (centred on year 1996, showing 1181 individuals) and exam 7 (year 2000, showing 1020 individuals). Each node represents one person (circles are female, squares are male). Lines between nodes indicate relationship (black for siblings, red for friends and spouses). Node colour denotes mean happiness of ego and all directly connected (distance 1) alters, with blue shades indicating least happy and yellow shades indicating most happy (shades of green are intermediate) average that people feel closer to the people they name than the people they do not name. By the same reasoning we expect on average that, in one way nominations, the namer feels closer to the namee than vice versa. We therefore hypothesised that the influence a friend has on an ego would be affected by the type of friendship, with the strongest effects occurring between mutual friends, followed by ego perceived friendships, followed by alter perceived friendships.

At inception, 53\% of the egos were women; the egos' mean age was 38 years (range 21-70); and their mean education was 1.6 years of college (range $0-\geq 17$ years of education). Measures of occupational prestige for each ego at each wave were also available (see appendix on bmj.com).

We studied 4739 of the 5124 egos who were alive in 1983 (which was the first time happiness was measured in the Framingham study). All participants were followed until 2003 (at exam 7), as were any ties to alters noted during the time period 1983-2003.

\section{Measures}

We took happiness to consist of positive emotions and used a conventional measure. We focused on individuals who were assessed with the Center for Epidemiological Studies depression scale (CES-D) in 19832003 at times corresponding to the 5 th, 6 th, and 7 th examinations of the offspring cohort. The median year of examination for these individuals was 1986 for exam 5, 1996 for exam 6, and 2000 for exam 7.

To measure happiness, we use four items from the CES-D in which people were asked how often they experienced certain feelings during the previous week: "I felt hopeful about the future," "I was happy," "I enjoyed life," "I felt that I was just as good as other people." This subcomponent of the CES-D has been shown to be a valid instrument for measuring positive affect, ${ }^{39-41}$ and it has been taken as interchangeable with the concept of happiness. ${ }^{42}{ }^{43}$ We defined "happy" as a perfect score on all four questions, but we obtain similar results if we treat happiness as a linear 0-12 scale that sums answers to all four questions (data not shown), with $0=$ rarely or none of the time ( $<1$ day/week), $1=$ some or a little of the time (1-2 days/week), $2=$ occasionally or a moderate amount of the time (3-4 days/week), and 3=most or all the time (5-7 days/ week). We performed confirmatory factor analysis and found that responses to these four questions were highly correlated with one another and therefore could be treated as additive measures of a single "happiness" scale, as documented by previous research (see appendix on bmj.com). ${ }^{39-41}$ The response rate among those who answered at least one question was $98.8 \%$. We imputed missing items using Amelia, a multiple imputation procedure. $^{44}$

We were interested not just in whether individuals were happy or not but also in changes in their happiness over time. We used the previous wave as a baseline measure and evaluated the probability of an ego being happy at a succeeding wave. At follow-up, the 
prevalence of happiness was $61 \%$ in exam 6 and $59 \%$ in exam 7. The mean index score was 10.7 in exam 6 and 10.6 in exam 7. Between exams 6 and 7, for example, $16 \%$ of individuals became happy, 13\% became unhappy, 49\% remained happy, and 22\% remained unhappy.

\section{Network analysis}

Social networks consist of two elements: individuals (nodes) and the relationships (social ties) between them. Once all the nodes and ties are known, one can draw pictures of the network and discern every person's position within it. Within a network, one can speak of the "distance" between two people (also known as the "geodesic distance" or "degree of separation"), which is the shortest path in the network from one person to another. For example, a person is one degree removed from their friend, two degrees removed from their friend's friend, three degrees removed from their friend's friend's friend, and so on. Often, real social networks contain collections of subnetworks or "components." A component is a part of a network in which everyone is connected by at least one path to every other person in the same component. Logically, this means that for two different components, no one in the first component can be connected to anyone in the second component. The basic idea in social network analysis is that individuals are influenced by their location in a social network and by the happenings among people who are "nearby" them in the social network (for example, at one, two, or three degrees of separation).

Once a full set of individuals and ties is observed, there is only one "network" per se. This network, however, can be analysed or drawn in various ways. For example, within this network, one might include only ties between people and their friends and spouses, or one might include only ties between family members. One might look at just the largest component or sample several hundred nodes from the network to study part of its structure more closely.

We used the Kamada-Kawai algorithm to prepare images of networks (fig 1). ${ }^{45}$ This algorithm is a visualisation tool that iteratively repositions nodes to reduce the number of ties that cross each other. The fundamental pattern of ties in a social network (known as the "topology") is fixed, but how this pattern is visually rendered depends on the analyst's objectives.

To test whether clustering of happy and unhappy people in the network is due to chance, we compared the observed clustering to the clustering in 1000 randomly generated networks in which we preserved the network topology and the overall prevalence of happiness but in which we randomly shuffled the assignment of the happiness value to each node. ${ }^{46}$ If clustering is occurring, then the probability that an alter is happy given that an ego is happy should be higher in the observed network than in the random networks. This procedure also allowed us to generate confidence intervals and measure how far, in terms of social

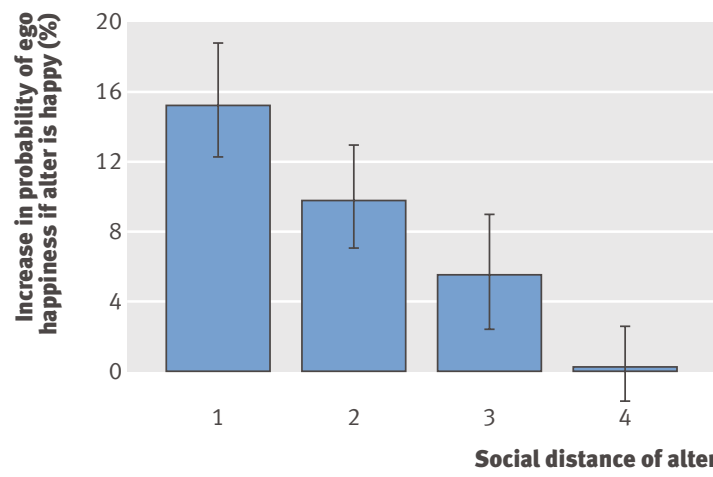

$\overline{\text { Fig } 2}$ | Social distance and happiness in the Framingham social network. Percentage increase in likelihood an ego is happy if friend or family member at certain social distance is happy (instead of unhappy). The relationship is strongest between individuals who are directly connected but remains significantly $>0$ at social distances up to three degrees of separation, meaning that a person's happiness is associated with happiness of people up to three degrees removed from them in the network. Values derived by comparing conditional probability of being happy in observed network with an identical network (with topology and incidence of happiness preserved) in which same number of happy people are randomly distributed. Alter social distance refers to closest social distance between alter and ego (alter=distance 1, alter's alter=distance 2, etc). Error bars show $95 \%$ confidence intervals

distance, the correlation in happiness between ego and alters reaches.

Measures of centrality in networks capture the extent to which a node connects, or lies between, other nodes, and hence its tendency to be positioned near the centre of his or her local network. Centrality is also taken as a marker of importance. The simplest measure of centrality is a count of the number of friends (this is called "degree" centrality). People with more friends will tend to be more central. But this measure does not account for differences in the centrality of one's friends. Individuals who are connected to many well connected peers are more central than those who are connected to an identical number of poorly connected peers. In other words, those who befriend popular people will tend to be more central than those who befriend the unpopular. We used eigenvector centrality to capture this aspect. ${ }^{47}$ This measure assumes that the centrality of a given person is an increasing function of the sum of all the centralities of all the people with whom he or she is connected (see appendix on bmj.com). Eigenvector centrality values are inherently relative: an individual connected to every other person in the network would have the maximum possible value, and a person not connected to anyone else would have a value of zero. In large networks, eigenvector centrality will not necessarily produce a measure of importance to the overall network but rather to a person's local network. It is therefore possible that the most central individuals might not necessarily be located near the centre of a visualisation of the whole network-instead they will be located at the centre of their local networks. 


\section{Statistical analysis}

The association between the happiness of individuals connected to each other, and the clustering within the network, could be attributed to at least three processes: induction, whereby happiness in one person causes the happiness of others; homophily, whereby happy individuals choose one another as friends and become connected (that is, the tendency of like to attract like) ${ }^{48}$; or confounding, whereby connected individuals jointly experience contemporaneous exposures (such as an economic downturn or living in the same neighbourhood $\left.^{13}\right)$. To distinguish between these effects requires repeated measures of happiness, ${ }^{3549}$ longitudinal information about network ties, and information about the nature or direction of the ties (for example, who nominated whom as a friend).

We evaluated regression models of ego happiness as a function of ego's age, sex, education, and happiness in the previous exam, and of the happiness of an alter in the current and previous exam. Inclusion of ego happiness in the previous exam helps to eliminate serial correlation in the errors and also substantially controls for ego's genetic endowment and any intrinsic stable predilection to be happy. Alter's happiness in the previous exam helps to control for homophily. ${ }^{3549} \mathrm{We}$ evaluated the possibility of omitted variables or contemporaneous events or exposures in explaining the associations by examining how the type or direction of the social relationship between ego and alter affects the association between them. If unobserved factors drive the association between ego and alter happiness, then directionality of friendship should not be relevant. We also examined the possible role of exposure to neighbourhood factors by examining maps (see appendix on bmj.com).

The main coefficient of interest in these regression models is the one related to contemporaneous happiness in alters - that is, the extent to which an alter's present happiness, net of the alter's previous happiness, is associated with an ego's present happiness, net

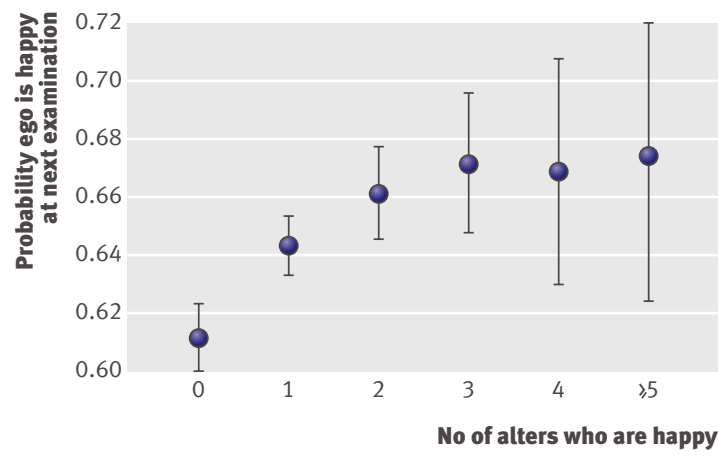

Fig 3 | Happy alters in Framingham social network. Mean probabilities observed in raw data with standard errors. Ego happiness in exams 6 and 7 (dichotomised between those who are maximally happy and everyone else) is positively associated with number of happy alters in previous exam. Generalised estimating equation regression models in appendix (see bmj.com) confirm relation is strongly significant, even with numerous controls of the ego's previous happiness. ${ }^{3549}$ We used generalised estimating equation procedures to account for multiple observations of the same ego across waves and across ego-alter pairings. ${ }^{50} \mathrm{We}$ assumed an independent working correlation structure for the clusters. ${ }^{51}$

The generalised estimating equation regression models provide parameter estimates in the form of $\beta$ coefficients (as shown in the appendix on bmj.com), whereas the results reported in the text and in figures 4 and 5 are in the form of risk ratios, which are related to the exponentiated coefficients. We calculated mean effect sizes and $95 \%$ confidence intervals by simulating first difference in alter contemporaneous happiness (changing from 0 to 1) using 1000 randomly drawn sets of estimates from the coefficient covariance matrix and assuming all other variables are held at their means. ${ }^{52}$

We explored the sensitivity of our results by conducting numerous other analyses, each of which had various strengths and limitations but none of which yielded substantially different results from those presented here (see appendix on bmj.com).

The networks in this study, like those in all network studies, are only partially observed. Therefore, there will be measurement error in individual network attributes. For example, we measured a person's centrality based on the observed social network, but that same person might be highly central to an unobserved network of individuals who did not take part in the study. If there is a correlation between this measurement error and happiness, it could bias our results. We evaluated this potential source of bias by measuring the Pearson correlation between the number of social relations named outside the Framingham Heart Study and subject happiness. The association was both small and not significant $(\rho=-0.01, \mathrm{P}=0.33)$, suggesting that the unobserved parts of the network do not bias the inferences we make within the observed network.

\section{RESULTS}

Examination of the social network indicates that happy people tend to be connected to one another. Figure 1 shows the largest connected network component in 1996 and 2000 based on a restricted set of ties among siblings, spouses, and friends (coworker and neighbours are excluded to simplify the image). To highlight the clustering of happiness, each node is coloured according to the person's happiness on a spectrum from blue (unhappy) to yellow (happy).

The clusters of happy and unhappy people seen in the network are significantly larger than expected by chance. We can calculate the relationship of ego and alter happiness at various degrees of separation by measuring the probability that an ego is happy when an alter is happy and comparing it to the same probability in a simulated network in which we retain the observed network ties and prevalence of happiness, but randomly shuffle the observed happiness between nodes. Figure 2 shows that the association between ego and alter happiness is significant up to three degrees of separation. A person is $15.3 \%$ (95\% confidence interval 
$12.2 \%$ to $18.8 \%$ ) more likely to be happy if a directly connected alter (distance 1) is happy. The effect for distance two alters is $9.8 \%(7.0 \%$ to $12.9 \%)$ and for distance three alters is $5.6 \%$ (2.4\% to $9.0 \%)$.

Figure 1 also suggests a relation between network centrality and happiness: people at the core of their local networks seem more likely to be happy, while those on the periphery seem more likely to be unhappy. We tested this by computing eigenvector centrality measures for each subject. Generalised estimating equation regressions show that ego centrality is significantly associated with improved future happiness: a 2 SD increase in centrality (from low to medium or medium to high) increases the probability of being happy at the next examination by $14 \%$ (1\% to $29 \%, \mathrm{P}=0.03)$. Moreover, the relation between centrality and future happiness remained significant even when we controlled for age, education, and the total number of family and non-family alters. Thus, it is not only the number of direct ties (at one degree of separation) but also the number of indirect ties (at higher degrees of separation) that influence future happiness. The better connected are one's friends and family, the more likely one will attain happiness in the future. Conversely, happiness itself does not increase a person's centrality at subsequent time points (see appendix on bmj.com). That is, network centrality leads to happiness rather than the other way around.

Figure 3 shows the positive association between the total number of happy alters and ego's future probability of being happy in the raw data. To test the relation more rigorously, we specified generalised estimating equation regression models of ego happiness with the number of happy and unhappy alters in the previous exam as key predictors. The relation is highly significant, with each happy alter increasing the probability the ego is happy by about $9 \%(\mathrm{P}=0.001)$, and each unhappy alter decreasing it by $7 \%(\mathrm{P}=0.004)$. Hence, on average, having additional social contacts is helpful to ego's happiness only if the extra social contacts are happy themselves. We also evaluated the simultaneous effect of total number of alters (whether happy or unhappy) and the fraction of alters who are happy. These models show that happy alters consistently influence ego happiness more than unhappy alters, and only the total number of happy alters remains significant in all specifications (see appendix on bmj.com). In other words, the number of happy friends seems to have a more reliable effect on ego happiness than the number of unhappy friends. Thus, the social network effect of happiness is multiplicative and asymmetric. Each additional happy alter increases the likelihood of happiness, but each additional unhappy alter has little or no effect. The emotional state of a person's social relationships is more important to one's own emotional state than the total number of those relationships.

We examined the direct ties and individual level determinants of ego happiness in more detail. The principal determinant of a person's happiness was their previous happiness; individuals who were happy at one

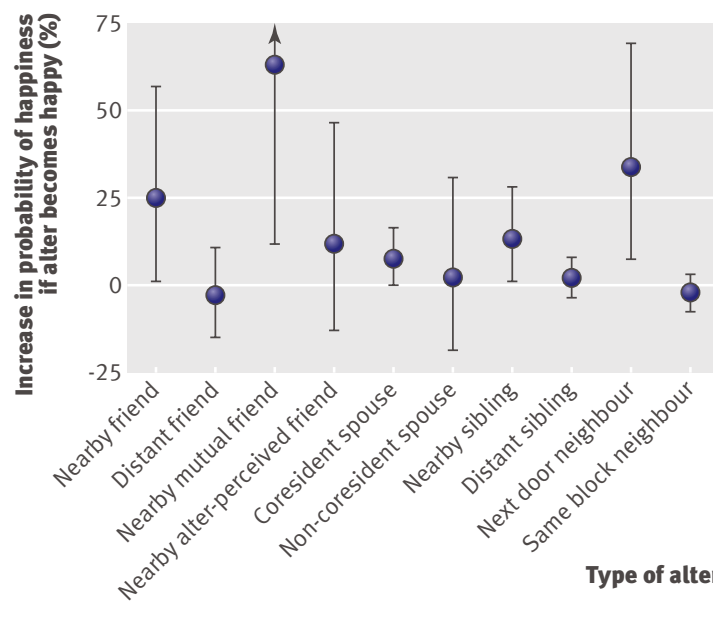

Fig $4 \mid$ Alter type and happiness in the Framingham social network. Friends, spouses, siblings, and neighbours significantly influence happiness, but only if they live close to ego. Effects estimated with generalised estimating equation logit models of happiness on several different subsamples of the network (see table 56 in appendix on bmj.com)

wave were roughly three times more likely than unhappy people to be happy at the subsequent observation. Age, sex, and education had effects consistent with previous research, with women being less happy then men and educated people being slightly happier (see appendix on bmj.com).

Our main interest was the impact on an ego of the happiness of others. Figure 4 shows the results of generalised estimating equation models that distinguish effects for friends, spouses, siblings, coworkers, and neighbours. We can use these results to estimate what would happen to the happiness of the ego if the alter were "switched" from being unhappy to being happy - that is, if the alters "become" happy. "Nearby" friends (who live within a mile $(1.6 \mathrm{~km})$ ) and who become happy increase the probability ego is happy by $25 \%$ (1\% to 57\%). "Distant" friends (who live more than a mile away) have no significant effect on ego. Among friends, we can distinguish additional possibilities; as each person was asked to name a friend, and not all of these nominations were reciprocated, we have ego perceived friends (denoted "friends"), "alter perceived friends" (alter named ego as a friend, but not vice versa) and "mutual friends" (ego and alter nominated each other). Nearby mutual friends have a stronger effect than nearby ego perceived friends; when they become happy it increases the probability ego will be happy by $63 \%(12 \%$ to $148 \%)$. In contrast, the influence of nearby alter perceived friends is much weaker and not significant $(12 \%,-13 \%$ to $47 \%)$. If the associations in the social network were merely caused by confounding, these effect sizes for different types of friendships should be more similar. That is, if some third factor were explaining both ego and alter happiness, it should not respect the directionality of the tie.

We also found similar effects for other kinds of alters. Coresident spouses who become happy increase the probability their spouse is happy by $8 \%(0.2 \%$ to $16 \%)$, 
while non-coresident spouses have no significant effect. Nearby siblings who live within a mile $(1.6 \mathrm{~km})$ and become happy increase their sibling's chance of happiness by $14 \%$ ( $1 \%$ to $28 \%$ ), while distant siblings have no significant effect. Next door neighbours who become happy increase ego's happiness by $34 \%$ (7\% to $70 \%$, while neighbours who live on the same block (within 25 metres) have no significant effect. All these relations indicate the importance of physical proximity, and the strong influence of neighbours suggests that the spread of happiness might depend more on frequent social contact than deep social connections. On the other hand, we found no effect of the happiness of coworkers on an ego, suggesting that the social context might moderate the flow of happiness from one person to another.

Past research on emotional contagion indicates that close physical proximity or coresidence is indeed necessary for emotional states to spread. ${ }^{23}$ To further explore whether distance affects the spread of happiness, we varied the cut off for nearby friends. Figure 5
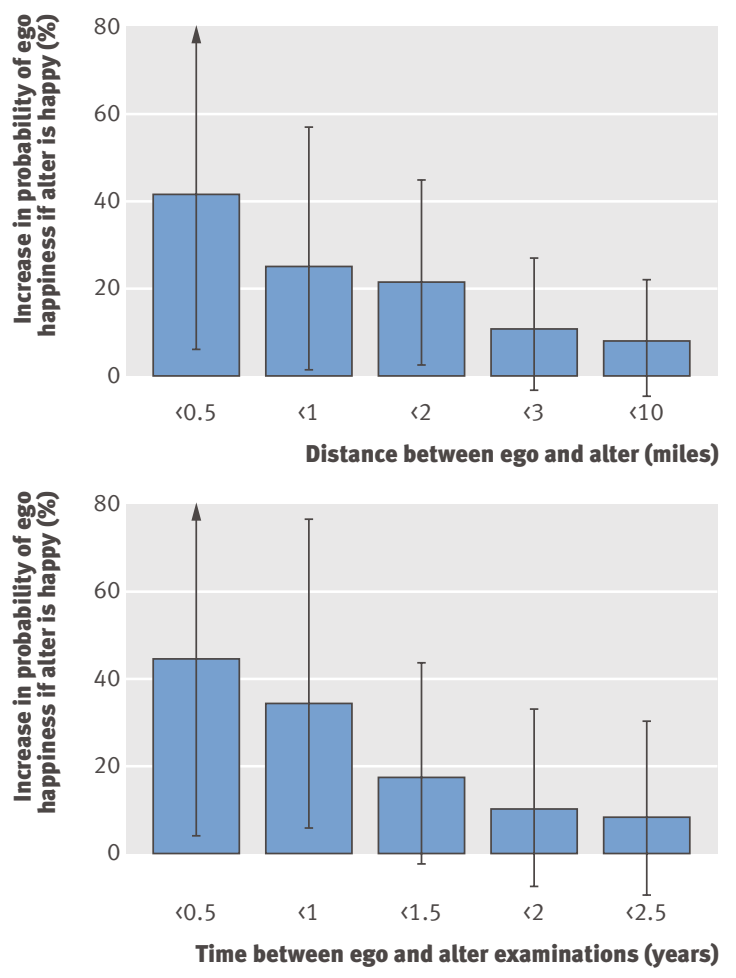

Fig 5 Physical and temporal separation and spread of happiness in Framingham social network. Figure shows probability that ego is happy given that alter friend is happy, for different subsamples. Top: effect of gradually increasing maximum distance allowed between ego and alter households. Friends who live less than half mile $(0.8 \mathrm{~km})$ away have the strongest effect on ego happiness, and effect decreases with distance. Bottom: effect of gradually increasing maximum time allowed between ego and alter exams. Friends who report becoming happy within past half year exert strongest influence on ego happiness, and effect decreases as time between ego and alter exams increases. Effect sizes are based on generalised estimating equation models of happiness in tables S9 and S10 in appendix on bmj.com (top) shows that the probability that an ego becomes happy in response to an alter varies for friends who live at different physical distances. An ego is $42 \%(6 \%$ to $95 \%$ ) more likely to be happy if a friend who lives less than half a mile $(0.8 \mathrm{~km})$ away becomes happy (net of controls, including ego's baseline happiness). In contrast, the effect is only $22 \%(2 \%$ to $45 \%)$ for friends who live less than two miles $(3.2 \mathrm{~km})$ away, and it declines and ceases to be significant at greater distances.

Past research also suggests that changes in happiness are temporary and that there is "hedonic adaptation" to diverse stimuli ${ }^{4}$ (in other words, people get used to good or bad fortune after some time). Figure 5 (bottom) shows such an effect for the interpersonal spread of happiness. An ego is $45 \%$ (4\% to $122 \%$ ) more likely to be happy if a friend who was examined in the past half year becomes happy. In contrast, the effect is only 35\% (6\% to $77 \%)$ for friends who were examined within the past year, and it declines and ceases to be significant at greater periods of time.

Sex also plays a part in the spread of happiness. Happiness spreads significantly more through same sex relationships than opposite sex relationships ( $\mathrm{P}=0.02$, see appendix on bmj.com), possibly helping to explain why friends and next door neighbours might exhibit stronger effects than spouses (who in our sample were all opposite sex). This result also accords with previous evidence on sex effects in the spread of obesity $^{3235}$ and suggests that people might be more likely to take emotional cues from members of the same sex.

Finally, similarity in socioeconomic status probably cannot explain the clustering of happy people as next door neighbours have a much stronger influence than neighbours who live a few doors down in the same neighbourhood (and who consequently have similar housing, wealth, and environmental exposures). Moreover, the geographical distribution of happiness is not systematically related to local levels of either income or education (see maps in appendix on bmj.com). Both of these observations suggest that contextual effects are probably not driving our results.

\section{DISCUSSION}

While there are many determinants of happiness, ${ }^{1-15}$ whether an individual is happy also depends on whether others in the individual's social network are happy. Happy people tend to be located in the centre of their local social networks and in large clusters of other happy people. The happiness of an individual is associated with the happiness of people up to three degrees removed in the social network. Happiness, in other words, is not merely a function of individual experience or individual choice but is also a property of groups of people. Indeed, changes in individual happiness can ripple through social networks and generate large scale structure in the network, giving rise to clusters of happy and unhappy individuals. These results are even more remarkable considering that 


\section{WHAT IS ALREADY KNOWN ON THIS TOPIC}

Previous work on happiness and wellbeing has focused on socioeconomic and genetic factors

Research on emotional contagion has shown that one person's mood might fleetingly

determine the mood of others

Whether happiness spreads broadly and more permanently across social networks is unknown

\section{WHAT THIS STUDY ADDS}

Happiness is a network phenomenon, clustering in groups of people that extend up to three degrees of separation (for example, to one's friends' friends' friends)

Happiness spreads across a diverse array of social ties

Network characteristics independently predict which individuals will be happy years into the future might yet find that a "three degrees of influence rule" applies to depression, anxiety, loneliness, drinking, eating, exercise, and many other health related activities and emotional states, and that this rule restricts the effective spread of health phenomena to three degrees of separation away from the ego.

Our findings have relevance for public health. To the extent that clinical or policy manoeuvres increase the happiness of one person, they might have cascade effects on others, thereby enhancing the efficacy and cost effectiveness of the intervention..$^{33}$ For example, illness is a potential source of unhappiness for patients and also for those individuals surrounding the patient. Providing better care for those who are sick might not only improve their happiness but also the happiness of numerous others, thereby further vindicating the benefits of medical care or health promotion.

There is of course a tradition of community approaches to mental health ${ }^{5758}$ but this longstanding concern is now being coupled with a burgeoning interest in health and social networks. ${ }^{59}$ More generally, conceptions of health and concerns for the wellbeing of both individuals and populations are increasingly broadening to include diverse "quality of life" attributes, including happiness. Most important from our perspective is the recognition that people are embedded in social networks and that the health and wellbeing of one person affects the health and wellbeing of others. This fundamental fact of existence provides a conceptual justification for the specialty of public health. Human happiness is not merely the province of isolated individuals.

We thank Laurie Meneades, Rebecca Joyce, Molly Collins, Marian Bellwood, and Karen Mutalik for the expert assistance required to build the analytical data. We thank Chris Dawes, Dan Gilbert, Tom Keegan, Erez Lieberman, Andrew Oswald, Mark Pachucki, and Holly Shakya for helpful suggestions regarding the manuscript.

Contributors: Both authors participated in the conception and design of the study, analysis and interpretation of data, drafting and revising the article, and its final approval. Both authors are guarantors.

Funding: This was work was supported by NIH (R-01 AG24448, P-01

AG031093) and by the Pioneer Portfolio of the Robert Wood Johnson

Foundation; NHLBI's Framingham Heart Study is supported by contract number N01-HC-25195. Neither author has a dependent relationship with any of the funding agencies.

Competing interests: None declared.

Ethical approval: This work was approved by the Harvard institutional review board; the parent Framingham Heart Study has separate IRB approval. All participants gave informed consent.

Provenance and peer review: Not commissioned; externally peer reviewed. change their behaviour towards others (for example, by being nicer or less hostile), or merely exude an emotion that is genuinely contagious (albeit over a longer time frame than previous psychological work has indicated). Psychoneuroimmunological mechanisms are also conceivable, whereby being surrounded by happy individuals has beneficial biological effects.

The spread of happiness seems to reach up to three degrees of separation, just like the spread of obesity ${ }^{32}$ and smoking behaviour. ${ }^{34}$ Hence, although the person to person effects of these outcomes tend to be quite strong, they decay well before reaching the whole network. In other words, the reach of a particular behaviour or mood cascade is not limitless. We conjecture that this phenomenon is generic. We
1 Easterlin RA. Explaining happiness. Proc Natl Acad Sci USA 2003;100:11176-83. perspective. Geneva: World Health Organization, 2004.

3 Delamothe T. Happiness. BM/ 2005;331:1489-90.

4 Kahneman D, Krueger AB, Schkade D, Schwarz N, Stone AA. Would you be happier if you were richer? A focusing illusion. Science 2006;312:1908-10.

5 Clark AE, Oswald AJ. Satisfaction and comparison income. J Public Econ 1996;61:359-81.

6 Csikszentmihaly M. Flow: the psychology of optimal experience. New York: Harper Collins, 1991.

7 Wilson TD, Meyers J, Gilbert DT. "How happy was I, anyway?" A retrospective impact bias. Soc Cogn 2003;21:421-46.

8 Canli R, Sivers H, Whitfield SL, Gotlib IH, Gabrieli JDE. Amygdal response to happy faces as a function of extraversion. Science 2002;296:2191.
2 De Gargino JP. Children's health and the environment: a global 
9 Gervais M, Wilson DS. The evolution and functions of laughter and humor: a synthetic approach. Q Rev Biol 2005;80:395-430.

10 Gardner J, Oswald AJ. Money and mental wellbeing: a longitudinal study of medium-sized lottery wins. J Health Econ 2007;26:49-60.

11 Clark A, Oswald A. Unhappiness and unemployment. Econ J 1994;104:648-59.

12 Graham C, Felton A. Inequality and happiness: insights from Latin America. J Econ Inequal 2006;4:107-22.

13 Subramanian SV, Kim D, Kawachi I. Covariation in the socioeconomic determinants of self rated health and happiness: a multivariate multilevel analysis of individuals and communities in the USA. J Epidemiol Community Health 2005;59:664-9.

14 Ubel PA, Loewenstein G, Jepson C. Whose quality of life? A commentary exploring discrepancies between health state evaluations of patients and the general public. Qual Life Res 2003;12:599-607.

15 Zivin K, Christakis NA. The emotional toll of spousal morbidity and mortality. Am J Geriatr Psychiatry 2007;15:772-9.

16 Lykken D, Tellegen A. Happiness is a stochastic phenomenon. Psychol Sci 1996;7:186-9.

17 Hatfield E, Cacioppo JT, Rapson RL. Emotional contagion. New York: Cambridge University Press, 1994.

18 Zajonc RB. Emotion and facial efference: an ignored theory reclaimed. Science 1985;5:15-21.

19 Surakka V, Hietanen JK. Facial and emotional reactions to Duchenne and non-Duchenne smiles. Int J Psychophysiol 1998;29:23-33.

20 Papa A, Bonanno GA. Smiling in the face of adversity: the interpersonal and intrapersonal functions of smiling. Emotion 2008;1:1-12.

21 Scollon CN, Kim-Prieto C, Diener E. Experience sampling: promise and pitfalls, strengths and weaknesses. J Happiness Stud 2003;4:5-34.

22 Laurenceau JP, Bolger N. Using diary methods to study marital and family processes. J Fam Psychol 2005;19:86-97.

23 Larson R, Richards MH. Divergent realities: the emotional lives of mothers, fathers, and adolescents. New York: Basic Books, 1994.

24 Howes MJ, Hokanson JE, Lowenstein DA. Induction of depressive affect after prolonged exposure to a mildly depressed individual. J Pers Soc Psychol 1985;49:1110-3.

25 Pugh SD. Service with a smile: emotional contagion in the service encounter. Acad Manag / 2001;44:1018-27.

26 Tsai WC, Huang YM. Mechanisms linking employee affective delivery and customer behavioural intentions. J Appl Psychol 2002;87:1001-8.

27 Newman MEJ. The structure and function of complex networks. SIAM Rev Soc Ind Appl Math 2003;45:167-256.

28 Nowak MA and Sigmund K. Evolution of indirect reciprocity. Nature 2005;437:1291-8

29 Bearman PS, Moody J, Stovel K. Chains of affection: the structure of adolescent romantic and sexual networks. Am J Soc 2004;110:44-91.

30 Liljeros F, Edling CR, Nunes Amaral LA, Stanely HE, Aberg Y. The web of human sexual contacts. Nature 2001;411:907-8.

31 Kossinets G, Watts DJ. Empirical analysis of an evolving social network. Science 2006;311:88-90.

32 Christakis NA, Fowler JH. The spread of obesity in a large social network over 32 years. N Engl I Med 2007;357:370-9.

33 Christakis NA. Social networks and collateral health effects. $B M J$ 2004;329:184-5.

34 Christakis NA, Fowler JH. The collective dynamics of smoking in a large social network. N Engl J Med 2008;358:2249-58.
35 Fowler JH, Christakis NA. Estimating peer effects on health in social networks. J Health Econ 2008;27:1400-5.

36 Dawber TR. The Framingham study: the epidemiology of atherosclerotic disease. Cambridge: Harvard University Press, 1980.

37 Feinleib M, Kannel WB, Garrison RJ, McNamara PM, Castelli WP. The Framingham offspring study: design and preliminary data. Prev Med 1975;4:518-52.

38 Campbell KE, Lee BA. Name generators in surveys of personal networks. Soc Networks 1991;13:203-21.

39 Thorson JA. The CES-D-4 or 5 factors. Bull Psychon Soc 1993;31:577.

40 Sheehan TJ. The measurement structure of the Center For Epidemiologic Studies depression scale. J Pers Assess 1995;64:507.

41 Joseph S. Factor-analysis of the Center For Epidemiologic Studiesdepression scale. Psychol Rep 1995;76:40.

42 Mroczek DK, Kolarz CM. The effect of age on positive and negative affect: a developmental perspective on happiness. J Pers Soc Psychol 1998;75:1333-49.

43 Lyubomirsky S, King L, Diener E. The benefits of frequent positive affect: does happiness lead to success? Psychol Bull 2005;131:803-55.

44 King G, Honaker J, Joseph A, Scheve K. Analyzing incomplete political science data: an alternative algorithm for multiple imputation. $\mathrm{Am}$ Polit Sci Rev 2001;95:49-69.

45 Kamada T, Kawai S. An algorithm for drawing general undirected graphs. Inf Process Lett 1989;31:7-15.

46 Szabo G, Barabasi AL. Network effects in service usage. http://lanl. arxiv.org/abs/physics/0611177.

47 Bonacich P. Factoring and weighing approaches to clique identification. J Math Sociol 1972;2:113-20.

48 McPherson M, Smith-Lovin L, CookJM. Birds of a feather: homophily in social networks. Ann Rev Sociol 2001;27:415-44.

49 Carrington PJ, Scott J, Wasserman S. Models and methods in social network analysis. Cambridge: Cambridge University Press, 2005.

50 Liang KY, Zeger SL. Longitudinal data analysis using generalized linear models. Biometrika 1986;73:13-22.

51 Schildcrout JS. Regression analysis of longitudinal binary data with time-dependent environmental covariates: bias and efficiency. Biostatistics 2005;6:633-52.

52 King G, Tomz M, Wittenberg J. Making the most of statistical analyses: improving interpretation and presentation. Am J Pol Sci 2000;44:341-55

53 Gilbert DT, Wilson TD. Prospection: experiencing the future. Science 2007;317:1351-4.

54 Keltner D, Bonanno GA. A study of laughter and dissociation: distinct correlates of laughter and smiling during bereavement. J Pers Soc Psychol 1997;73:687-702.

55 Goodall J. The behaviour of free-living chimpanzees in the Gombe Stream Reserve. Anim Behav Monogr 1968;1:165-311.

56 Silk JB. Social components of fitness in primate groups. Science 2007;317:1347-51.

57 Pescosolido BA, Gardner CB, Lubell KM. How people get into mental health services: stories of choice, coercion and 'muddling through' from 'first-timers.' Soc Sci Med 1998;46:275-86.

58 Ross N. Health, Happiness, and higher levels of social organization. J Epidemiol Community Health 2005;59:614.

59 Smith KP, Christakis NA. Health and social networks. Annu Rev Sociol 2008;34:405-29.

Accepted: 10 September 2008 